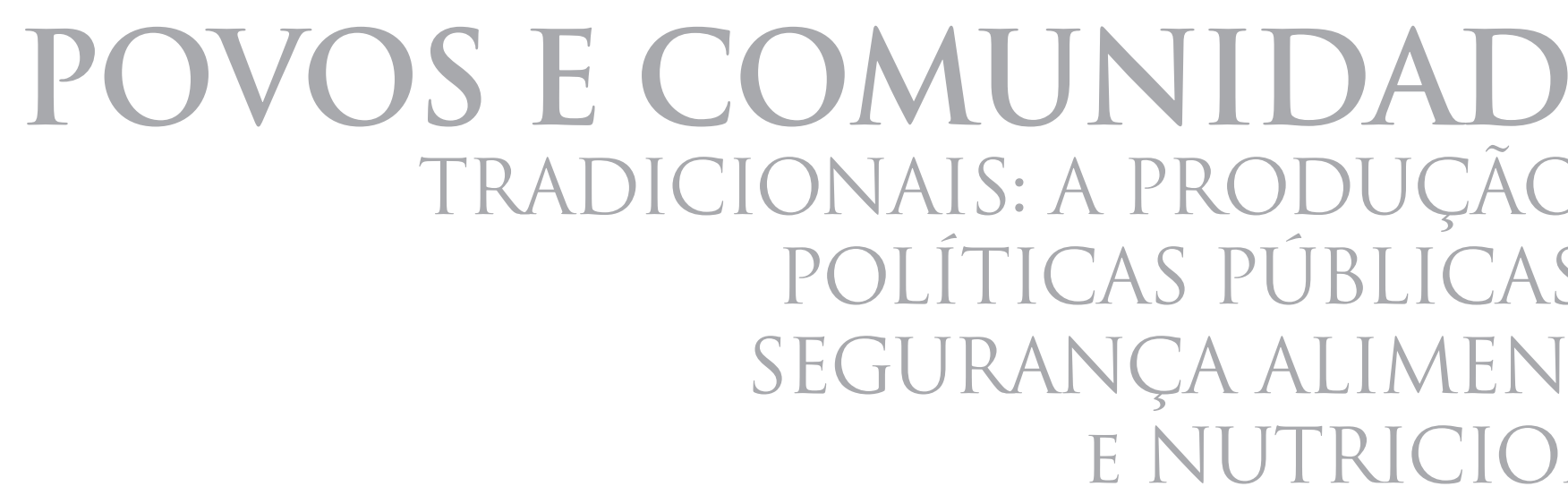




\section{POVOS E COMUNIDADES TRADICIONAIS: A PRODUÇÃO DE POLÍTICAS PÚBLICAS DE SEGURANÇA ALIMENTAR E NUTRICIONAL}

\section{R I O L U I Z C O N T I}

UNIVERSIDADE FEDERAL DO RIO GRANDE DO SUL, BRASIL

$$
\text { GABRIELA COELHO-DE-SOUZA }
$$




\title{
POVOS E COMUNIDADES TRADICIONAIS: A PRODUÇÃO DE POLÍTICAS PÚBLICAS DE SEGURANÇA ALIMENTAR E NUTRICIONAL
}

\begin{abstract}
Resumo
Este estudo visa analisar a construção conceitual sobre povos e comunidades tradicionais nos marcos regulatórios e nas ciências sociais e ambientais, compreender como suas demandas são internalizadas pelo Conselho Nacional de Segurança Alimentar e Nutricional (Consea) e em que medida são transformadas em proposições de políticas públicas pelo governo federal no Plano Nacional de Segurança Alimentar e Nutricional.

Palavras-chave: povos e comunidades tradicionais, povos indígenas, direitos humanos, diversidade étnica, segurança alimentar e nutricional.
\end{abstract}

\section{INDIGENOUS AND TRADITIONAL COMMUNITIES: THE PRODUCTION OF PUBLIC POLICIES FOR FOOD SECURITY AND NUTRITION}

\begin{abstract}
This study aims to analyze the conceptual construction of traditional communities in regulatory frameworks and in social and environmental sciences. Besides it aims to understand how their demands are internalized by the Conselho Nacional de Segurança Alimentar e Nutricional in Brazil (Consea), and to analyze which demands are transformed into public policy propositions by the federal government.
\end{abstract}

Keywords: traditional communities, indigenous, human rights, ethnic diversity, food security and nutrition. 


\section{PUEBLOS Y COMUNIDADES TRADICIONALES: LA PRODUCCIÓN DE POLÍTICAS PÚBLICAS PARA LA SEGURIDAD ALIMENTARIA Y NUTRICIONAL}

\section{Resumen}

Este estudio tiene como objetivo analizar la construcción conceptual de las comunidades tradicionales en los marcos normativos y en las ciencias sociales y ambientales. También comprehender como sus demandas son internalizados por el Consejo Nacional de Seguridad Alimentaria y Nutricional (Consea) y en qué medida se transforman en propuestas de políticas públicas por el gobierno federal en el Plan Nacional de Alimentación y Seguridad Alimentaria y Nutricional.

Palabras clave: comunidades tradicionales, pueblos indígenas, derechos humanos, diversidad étnica, seguridad alimentaria y la nutricional

Endereço do primeiro autor para correspondência: Programa de PósGraduação em Desenvolvimento Rural, Universidade Federal do Rio Grande do Sul, Av. João Pessoa, 31, CEP 90.040-000. E-mail: irio@ ifibe.edu.br 
Nas três últimas décadas emergem novos atores sociais na sociedade brasileira entre os quais se encontram os povos indígenas e os povos e comunidades tradicionais. Tanto a literatura das ciências sociais e ambientais, quanto o marco jurídico-normativo têm avançado no sentido de localizar e definir essas populações no contexto social, político, econômico, cultural e ambiental. Recentemente, a partir da década de 2000, a diversidade cultural, incluindo a questão dos povos indígenas e povos e comunidades tradicionais, passou a ser pautada no âmbito das políticas de segurança alimentar e nutricional.

Este estudo visa analisar a construção conceitual sobre povos e comunidades tradicionais, compreender como suas demandas são internalizadas pelo Conselho Nacional de Segurança Alimentar e Nutricional (Consea) e em que medida são transformadas em proposições de políticas públicas pelo governo federal no Plano Nacional de Segurança Alimentar e Nutricional.

$\mathrm{Na}$ sequência de uma breve revisão teórica serão analisados nove documentos denominados Exposições de Motivos (cinco) e Recomendações (quatro) que foram discutidos, elaborados e aprovados no interior do Consea Nacional no período de 2008 a 2012, que tratam de temas relevantes e pertinentes aos povos e comunidades tradicionais. ${ }^{1}$ Faz-se uma leitura analítica desses documentos que foram enviados à Presidência da República para identificar suas principais demandas ao governo. Finalmente se fará uma lei- tura do Plano Nacional de Segurança Alimentar e Nutricional para perscrutar em que medida as reivindicações dos povos e comunidades tradicionais, transformadas e encaminhadas pelo Consea ao governo, se traduzem em políticas públicas de cumprimento dos direitos dessas populações no que tange à realização do direito humano à alimentação adequada e saudável.

\section{POVOS E COMUNIDADES TRADICIONAIS: EMERGÊNCIA E VISIBILIDADE}

A noção de povos e comunidades tradicionais (PCTs) é relativamente recente na literatura acadêmica e na esfera governamental e social. Trata-se da emergência de uma diversidade de atores sociais que, segundo Costa Filho (2007), surgiu no seio da problemática ambiental e no contexto de criação das unidades de conservação pelos órgãos ambientais, para responder à complexa situação das populações tradicionais que residiam nessas áreas de interesse para conservação.

Por tratar-se de uma noção que está em construção, desde a década de 1990, há uma evolução na compreensão e uso do termo. Alguns autores como Diegues (1996), Santilli (2005), Cunha \& Almeida (2001) e Barreto Filho (2001) chamam de populações tradicionais. Vianna (2004) usa o termo no singular população tradicional, Little (2002), Dayrel et al. (2012) preferem usar povos tradicionais e, ainda, outros chamam de comunidades tradicionais, comunidades locais e, finalmente, povos e comunidades tradicionais (PCTs), como consta na recente 
Política Nacional de Desenvolvimento Sustentável dos Povos e Comunidades Tradicionais (Brasil 2007).

Povos indígenas se diferenciam de povos e comunidades tradicionais, principalmente, por apresentarem uma característica histórica distintiva que é o fato de descenderem de populações que habitavam o atual Estado brasileiro no momento do contato com civilizações europeias e da colonização (Coelhode-Souza \& Kubo no prelo). Por este motivo, juntamente com os quilombolas, seus direitos foram reconhecidos na Constituição Federal de 1988 (Brasil 2011a). Os povos e comunidades tradicionais passaram a ser reconhecidos como categoria após este período, na esteira dos espaços conquistados pelos povos indígenas e quilombolas, reconhecidos por suas características étnicas.

Neste trabalho optou-se pela utilização de "povos e comunidades tradicionais" por entender-se que este seja o termo atualmente adotado nas políticas públicas mais recentes, estando de acordo com a finalidade deste estudo, que visa relacioná-lo com as políticas públicas em segurança alimentar e nutricional (SAN). Entretanto, antes serão trazidos elementos que contribuem para a compreensão de PCTs desde as abordagens jurídico-normativas e das ciências sociais.

\section{POVOSE COMUNIDADES TRADICIONAIS: ABORDAGEM JURIIDICO-NORMATIVA}

A promulgação da Constituição Federal de 1988 foi um marco histórico e jurídico importante na formação da nação brasileira porque, segundo Dayrell et al. (2012), nela o Brasil passou a reconhecer a diversidade cultural como constituinte e constitutiva da nacionalidade brasileira. Em seus artigos 215 e 216 a Constituição Federal garante o direito à cultura. O Artigo 215 determina, em seu caput, que "o Estado garantirá a todos o pleno exercício dos direitos culturais e o acesso às fontes da cultura nacional, e apoiará e incentivará a valorização e a difusão das manifestações culturais". E o parágrafo primeiro do mesmo artigo define que "o Estado protegerá as manifestações das culturas populares, indígenas e afro-brasileiras, e das de outros grupos participantes do processo civilizatório nacional", que é completado pelo parágrafo $5^{\circ}$ do $\mathrm{Ar}$ tigo 216, que deixa claro o tombamento de "documentos e sítios detentores de reminiscências históricas dos antigos quilombos". Já, o Artigo 216 define o que constitui o patrimônio cultural que precisa ser protegido:

"Constitui patrimônio cultural brasileiro os bens de natureza material e imaterial, tomados individualmente ou em conjunto, portadores de referência à identidade, à ação, à memória dos diferentes formadores da sociedade brasileira, nos quais se incluem: I - as formas de expressão; II - os modos de criar, fazer e viver; III - as criações científicas, artísticas e tecnológicas; IV - as obras, objetos, documentos, edificações e demais espaços destinados às manifestações artístico-culturais; $\mathrm{V}$ - os conjuntos urbanos e sítios de valor histórico, paisagístico, artístico, arqueológico, paleontológico, ecológico e cientí- 
fico" (Brasil 1988, Art. 216).

No plano internacional, em 1992, na Conferência das Nações Unidas realizada no Rio de Janeiro, foi aprovada a Convenção sobre a Diversidade Biológica, que passou a ser adotada a partir de 1993 pelos estados membros da ONU e o Brasil a ratificou e adotou em 1994 (Brasil 2000a). Esta Convenção estabelece que os Estados devem respeitar, preservar e manter o conhecimento, inovações e práticas dos povos indígenas e comunidades locais com seus hábitos culturais e estilos de vida tradicionais relevantes à conservação e à utilização sustentável da diversidade biológica e que os detentores desses conhecimentos devem ter participação ativa em sua gestão (artigo 8-j). A Convenção utiliza os termos "comunidades locais" e "estilos de vida tradicionais", mas não define precisamente seus conteúdos, o que com frequência também ocorre com a literatura internacional, que utiliza bastante o termo comunidades locais, de acordo com as realidades específicas.

Outro instrumento normativo importante é a Convenção 169 da Organização Internacional do Trabalho (OIT) sobre Povos Indígenas e Tribais, ${ }^{2}$ adotada em junho de 1989, ratificada pelo governo brasileiro em 2002 e que entrou em vigor no Brasil a partir de 2004 (Brasil 2004). Esta Convenção reconhece em seu artigo $1^{\circ}$ que a "autoidentificação como indígena ou tribal deverá ser considerada um critério fundamental para a definição dos grupos aos quais se aplicam às disposições da presente Convenção" (OIT, art. $1^{\circ}$ par. $\left.2^{\circ}\right)$. E o artigo $8^{\circ}$ complementa o artigo $1^{\circ}$ ao afirmar que os costumes ou leis consuetudinárias dos povos deverão ser levados na devida consideração (par. $1^{\circ}$ ) e que esses povos "terão o direito de manter seus costumes e instituições, desde que não sejam incompatíveis com os direitos fundamentais previstos no sistema jurídico nacional e com direitos humanos internacionalmente reconhecidos" (OIT, art. $8^{\circ}$ par. $2^{\circ}$ ). Com a afirmação deste princípio da autoidentificação fortalecem-se os fatores étnicos e as identidades coletivas, ao mesmo tempo em que se potencializam atores sociais que historicamente eram mantidos na invisibilidade e agora emergem como sujeitos de direitos.

No plano nacional, na virada deste século iniciou-se o que Santilli (2005) chama de um dos paradigmas socioambientais fundamentais, com a promulgação da Lei ${ }^{\circ}$ 9.985/2000 (Brasil 2000b), que institui o Sistema Nacional de Unidades de Conservação da Natureza (SNUC) e articula biodiversidade e sociobiodiversidade. E mais, cria-se um sistema de conservação que visa promover a interação harmoniosa entre o ser humano e a natureza e que, entre suas diretrizes, contempla a criação de condições para a "proteção aos recursos naturais necessários à subsistência de populações tradicionais, respeitando e valorizando seu conhecimento e sua cultura e promovendo-as social e economicamente" (Brasil, Lei no 9.985/2000, art. $\left.5^{\circ}\right)$, por meio das Reservas Extrativistas e Reservas de Desenvolvimento Sustentável. Neste contexto, há a união dos interesses pela conservação da natureza e pelo respeito e valorização das comunidades. As comunidades que vivem nas áreas ou manejam os recursos têm prevista a sua participação efetiva em todas as etapas da 
criação das unidades de conservação, de tal forma que aquelas que dependem dos recursos dessas áreas para obterem seus meios de subsistência os tenham garantidos ou sejam justamente indenizadas pelos prejuízos decorrentes da impossibilidade de seu manejo e uso sustentável.

Segundo Santilli (2005), o conceito de "populações tradicionais", que estava estabelecido no inciso XV do artigo $2^{\circ}$ da Lei que institui o SNUC, foi vetado pelo Poder Executivo por dois motivos: porque determinados grupos humanos não podem ser definidos como população tradicional simplesmente por habitarem continuadamente um mesmo ecossistema; e porque o número de gerações sobre um território não é o único critério para definir quem é e quem não é população tradicional.

Entretanto, gradualmente documentos da legislação nacional, ainda que de modo um tanto fragmentado, passam a dar o teor do que se entende por populações tradicionais. A Medida Provisória $n^{\circ}$ 2.186/2001 (Brasil 2001)- que regra o acesso ao patrimônio genético e ao conhecimento tradicional - se refere à "comunidade local" como um grupo humano que se organiza, tradicionalmente, incluindo remanescentes de comunidades quilombolas, por gerações sucessivas e costumes próprios.

A Portaria no 22/1992 (Brasil 1992), que criou o Centro Nacional do Desenvolvimento Sustentado das Populações Tradicionais, menciona "comunidades que tradicional e culturalmente têm sua subsistência baseada no extrativismo de bens naturais renováveis". O Decreto $\mathrm{n}^{\mathrm{o}} 98.897 / 1990$ reconhece as reservas extrativistas como "espaços territoriais destinados à exploração autossustentável e conservação dos recursos naturais renováveis por população extrativista".

E, para completar, a própria Lei do SNUC define que "Reserva Extrativista é uma área utilizada por populações extrativistas tradicionais, cuja subsistência baseia-se no extrativismo e, complementarmente, na agricultura de subsistência" (Brasil, Lei n ${ }^{\circ} 9.985 / 2000$, art. 18) e na criação de animais de pequeno porte, com objetivos básicos de proteger os meios de vida e a cultura dessas populações. A mesma lei define que:

"Reserva de Desenvolvimento Sustentável é uma área natural que abriga populações tradicionais, cuja existência baseia-se em sistemas sustentáveis de exploração dos recursos naturais, desenvolvidos ao longo de gerações e adaptados às condições ecológicas locais e que desempenham um papel fundamental na proteção da natureza e na manutenção da diversidade biológica" (Brasil, Lei $\mathrm{n}^{\circ} 9.985 / 2000$, art. 20).

No intervalo de tempo entre o início da década de 1990 e 2007 diversas portarias, decretos, resoluções e medidas provisórias com caráter específico em relação a povos indígenas, quilombolas, extrativistas, pescadores e outros povos e comunidades tradicionais foram editados. Tais medidas normativas, resultantes de mobilizações sociais e processos de consertação social, de alguma forma, contribuíram para se avançar em torno de definições jurídico-normativas convergentes de proteção e promoção dos direitos dessas populações emergentes. Finalmente, em 2007 o Estado brasileiro 
deu um passo expressivo no sentido de responder com ações públicas às demandas de uma diversidade de populações até então pouco visibilizadas, através do Decreto $n^{\circ}$ 6.040/2007 (Brasil 2007), que institui a Política Nacional de Desenvolvimento Sustentável dos Povos e Comunidades Tradicionais (PNPCT). A noção de povos e comunidades tradicionais já fica explícita no próprio nome do Decreto e em seu artigo $1^{\circ}$ que institui a PNPCT, mas o seu artigo $2^{\circ}$ dá um passo adiante ao definir as competências da Comissão Nacional de Desenvolvimento Sustentável dos Povos e Comunidades Tradicionais, criada em 2004 e formalmente instituída pelo Decreto de 13 de julho de 2006 (Brasil 2006), com a finalidade de coordenar a implementação da Política Nacional para o Desenvolvimento Sustentável dos Povos e Comunidades Tradicionais. E, na sequência, o Decreto apresenta a seguinte definição:

"I - Povos e Comunidades Tradicionais: grupos culturalmente diferenciados e que se reconhecem como tais, que possuem formas próprias de organização social, que ocupam e usam territórios e recursos naturais como condição para sua reprodução cultural, social, religiosa, ancestral e econômica, utilizando conhecimentos, inovações e práticas gerados e transmitidos pela tradição" (Brasil, Decreto $6.040 / 2007$, art. $3^{\circ}$ par. I).

Segundo Santilli (2005) e Dayrell et al. (2012), o SNUC e a PNPCT incorporam no ordenamento jurídico a contribuição das ciências sociais, especialmente ao inter-relacionar biodiversidade com sociodiversidade. Aos poucos esta visão penetra nos documentos jurídicos e normativos posteriores, de modo que a noção de povos e comunidades tradicionais reúne um crescente consenso entre os espaços da gestão pública para definir a diversidade de atores sociais congregados neste debate. Avaliações empíricas ainda incipientes permitem especular-se sobre a possibilidade de que - pela sua forte influência na implementação de políticas públicas para os diferentes atores sociais demandantes das mesmas - aos poucos, a noção de povos e comunidades tradicionais esteja galgando, entre a diversidade de atores sociais, um consenso similar àquele já bastante consolidado na linguagem da gestão pública.

\section{POVOS E COMUNIDADES TRADICIONAIS: ABORDAGEM DESDE AS CIÊNCIAS SOCIAIS E AMBIENTAIS}

A noção de povos e comunidades tradicionais (PCTs) é relativamente recente na literatura das ciências sociais, como também no contexto das políticas públicas e das organizações sociais. Esta seção traz contribuições das ciências sociais e ambientais, especialmente da antropologia, para a conformação da noção que está sendo consolidada.

Barreto Filho (2001) acentua que a noção de populações tradicionais tem sua emergência com o surgimento de comunidades diferenciadas como atores políticos cuja existência se caracteriza e está vinculada ao campo do conservacionismo e à ascensão das unidades de conservação a partir da década de 1990. Em uma perspectiva diferente, Little (2002) analisa essa emergência dos povos e comunidades tradicionais, associada ao 
contexto de demandas na área fundiária e às reivindicações de afirmação de direitos territoriais de grupos diferenciados frente ao Estado brasileiro, agora com uma forte conotação de serem detentores de territórios tradicionais coletivos, que de modo mais amplo remete para o sistema de posse e uso comunal. Segundo Dayrell et al. (2012:418), com ênfases diferenciadas os dois antropólogos anteriormente referidos discutem "a diversidade sociocultural do Brasil, que se expressa na pluralidade de formas de uso e apropriação do ambiente ou de territorialidades específicas que tendem a ser reunidas sob a denominação de povos tradicionais".

Santilli (2005) destaca que a noção de populações tradicionais é abrangente, tem seu nascedouro e expansão nas ciências sociais e relaciona-se à utilização de técnicas ambientais de baixo impacto, com formas de organização e representação sociais equitativas. Para Cunha \& Almeida:

"O emprego do termo "populações tradicionais" é propositalmente abrangente. Contudo, essa abrangência não deve ser confundida com confusão conceitual. Definir as populações tradicionais pela adesão à tradição seria contraditório com os conhecimentos antropológicos atuais. Defini-las como populações que têm baixo impacto sobre o ambiente, para depois afirmar que são ecologicamente sustentáveis, seria tautologia. Se as definirmos como populações que estão fora da esfera do mercado, será difícil encontrá-las hoje em dia.

(...)
No momento, a expressão "populações tradicionais" ainda está na fase inicial de sua vida. Trata-se de uma categoria pouco habitada, mas já conta com alguns membros e candidatos à entrada. Para começar, tem existência administrativa: o Centro Nacional de Populações Tradicionais, um órgão do Ibama. No início, a categoria congregava seringueiros e castanheiros da Amazônia. Desde então expandiu-se, abrangendo outros grupos, que vão de coletores de berbigão de Santa Catariana a babaçueiras do sul do Maranhão e quilombolas do Tocantins. O que todos esses grupos possuem em comum é o fato de que tiveram pelo menos em parte uma história de baixo impacto ambiental e de que têm no presente interessses em manter ou recuperar o controle sobre o território que exploram. E, acima de tudo, estão dispostos a uma negociação: em troca do controle sobre o território, comprometem-se a prestar serviços ambientais" (Cunha \& Almeida 2013:1).

Estes mesmos autores entendem que existe, ainda, outro fator fundamental que caracteriza as populações tradicionais, que vem se forjando ao longo das três últimas décadas como resultado de processos organizativos sociais, e se expressa na constituição de identidades diferenciadas daquelas às quais historicamente essas populações eram enquadradas. Segundo os autores:

"Já podemos afirmar que as populações tradicionais são grupos que conquistaram ou estão lutando para conquistar (através de meios práticos e simbólicos) uma identidade pública que inclui algumas e não necessariamente todas as seguintes característi- 
cas: o uso de técnicas ambientais de baixo impacto, formas equitativas de organização social, a presença de instituições com legitimidade para fazer cumprir suas leis, liderança local e, por fim, traços culturais que são seletivamente reafirmados e reelaborados "(Cunha \& Almeida 2013:1).

Por sua vez, Diegues \& Arruda (2001), ao descreverem as populações tradicionais, distinguem-nas em indígenas e não indígenas e realçam suas principais características: relação simbiótica entre ser humano e natureza; conhecimento profundo dos ciclos da natureza e manejo sustentável dos recursos naturais; território como espaço de reprodução econômica e social; ocupação do território por várias gerações; produção para a subsistência, baixa relação com o mercado e reduzida acumulação de capital; uso de tecnologias simples e de baixo impacto no ambiente; baseadas na unidade familiar, doméstica ou comunal; importância das simbologias, ritos e mitos inseparáveis da vida cotidiana; fraco poder político; autoidentificação ou identificação por outros pelo pertencimento a uma cultura distinta. A partir dessas características os autores definem populações tradicionais como:

"Grupos humanos diferenciados sob o ponto de vista cultural, que reproduzem historicamente seu modo de vida, de forma mais ou menos isolada, com base na cooperação social e relações próprias com a natureza. Tal noção refere-se tanto a povos indígenas quanto a segmentos da população nacional, que desenvolveram modos particulares de existência, adaptados a nichos ecológicos específicos" (Diegues \& Arruda 2001:27).
A diferenciação entre povos indígenas e povos e comunidades tradicionais, pautada no processo histórico, implica em relações diferenciadas com o Estado. $\mathrm{O}$ legado histórico garante aos povos indígenas o direito aos seus territórios originários, sem a imposição pelo Estado de que desenvolvam práticas sustentáveis de manejo dos recursos naturais que garantam a conservação das áreas, como é o caso da negociação que as populações tradicionais assumem para o acesso a seus territórios (Coelho-de-Souza \& Kubo no prelo).

Em estudos recentes Dayrell et al. (2012) trabalham com cinco questões estreitamente imbricadas que caracterizam os povos e comunidade tradicionais e sobre as quais se embasam seus direitos: identidade, organização social, território, sistema de produção e cultura, que serão sumarizados a seguir.

A identidade tem seu foco na autodefinição identitária que cada grupo dos povos e comunidades tradicionais faz de si mesmo, mas também em contraposição a outros grupos com os quais se relaciona, de modo que a identidade coletiva se caracteriza a partir dos aspectos que demarcam as diferenças intergrupais. Essa dimensão identitária é indissociável da base territorial e do pertencimento a um espaço, com condutas de territorialidades que se constituem com base em critérios de inclusão e exclusão dos respectivos grupos e famílias.

A organização estruturante da vida social desses grupos e comunidades se alicerça na família, base da organização comunitária que se afirma como uma coligação de famílias que estruturam as 
relações grupais e sociais. Por sua vez, a reprodução social ocorre em um espaço socialmente construído e apropriado, que é o território coletivo que se conforma de acordo com as tradições de cada grupo. Essas formas de construção e apropriação do território garantem a reprodução material, social e simbólica de cada grupo social na interação com a natureza.

O sistema de produção e a economia dos povos e comunidades tradicionais são construídos e dinamizados por cada grupo social a partir do princípio da economia da reciprocidade, com a finalidade de garantir os meios para a sua reprodução familiar e social. O trabalho e a produção são estruturados a partir de um conhecimento profundo da natureza e seus ciclos, com sobreposição dos calendários religioso e agrícola, fortemente embasados no manejo dos recursos naturais e em relações de trocas e cooperação. Assim, exercem um papel importante na articulação da coesão social de cada grupo desde a ocupação de múltiplos espaços produtivos e de múltiplas atividades produtivas, mas que cumprem a função primeira de garantir a subsistência e, secundariamente, a comercialização de seus excedentes para a agregação de renda para o seu sustento. Em convergência com esta última característica destacada pelos autores citados, Little (2005) identifica cinco micromodelos de relação dos povos e comunidades tradicionais com o mercado interconectadas entre si: o fortalecimento das atividades de subsistência; o estabelecimento de economias paralelas; a terceirização das atividades produtivas com fiscalização por parte do grupo local; o controle total do processo econômico por parte da organização local; e a criação de um valor econômico étnico para seus produtos.

Para Dayrell et al. (2012), a cultura e as manifestações culturais são transmitidas oralmente através das gerações, com base nos conhecimentos construídos ao longo da história de cada grupo ou comunidade. Existe uma grande diversidade de expressões culturais, tanto por meio da linguagem específica quanto de festas, rezas, comidas, vestimentas, estilos de vida, manejos da agrobiodiversidade, modos de construir as habitações e outras que se constituem em importantes marcadores identitários e de diferenciação com outros grupos sociais e comunidades, de tal forma a distinguir a especificidade na diversidade. Little (2005:41) complementa que "no plano político os apelos à autonomia cultural procuram eliminar os fortes vestígios do 'colonialismo interno' que ainda orientam as relações interétnicas em muitos países latinoamericanos".

De acordo com Hissa (2008), atualmente as fronteiras disciplinares estão cada vez mais fluídas, principalmente no campo dos saberes ambientais. Temáticas que anteriormente eram tratadas exclusivamente no âmbito das ciências sociais passaram a pertencer às questões ambientais, tais como diversidade étnica e cultural, conflitos territoriais e pobreza, sendo abordadas de forma interdisciplinar. Ao mesmo tempo, campos do conhecimento na interface entre antropologia e ecologia, perpassados pelo conhecimento tradicional, como a Etnoecologia (Coelho-de-Souza 
et al. 2011), tiveram um grande avanço. Esta área do conhecimento transfronteiriço, ao resgatar, valorizar e compreender a ecologia de povos indígenas e povos e comunidades tradicionais se alia ao esforço das ciências sociais no fortalecimento das identidades étnicas, bem como nas demandas desses grupos em relação ao Estado.

\section{INTERNALIZAÇÃO DAS DEMANDAS DOS POVOS E COMUNIDADES TRADICIONAIS PELO CONSEA NACIONAL}

O Conselho Nacional de Segurança Alimentar e Nutricional (Consea) foi criado em 1993 pelo Presidente Itamar Franco e extinto em 1994 pelo Presidente Fernando Henrique Cardoso. Foi recriado em 2003, pelo Presidente Luiz Inácio da Silva, e conta com 39 representantes da sociedade civil e 19 representantes governamentais. É um conselho de assessoramento da Presidência da República e tem como atribuição principal a proposição de políticas públicas de segurança alimentar e nutricional para os diversos segmentos da sociedade brasileira. Sua organização e dinâmica de atuação baseiam-se em reuniões de grupos de trabalhos, comissões temáticas, plenárias gerais e conferências nas quais são debatidas e aprovadas diretrizes, definições e recomendações que, por sua vez, são encaminhadas à Presidência da República e aos órgãos públicos responsáveis pela implementação de políticas e ações em SAN.

Normalmente as decisões do Consea são encaminhadas ao governo no formato de Exposições de Motivos e Reco- mendações. As primeiras são documentos políticos mais gerais e amplamente preparados, enquanto as recomendações consistem em documentos mais urgentes sobre demandas emergentes. Ambos reúnem proposições ao governo para que sejam tomadas as devidas providências governamentais em relação aos temas em questão. A seguir destacam-se as principais Exposições de Motivos e Recomendações, no período de 2008 a 2012, nas quais o Consea acolhe as reivindicações dos povos e comunidades tradicionais relacionadas à SAN e as transforma em demandas ao governo.

A Exposição de Motivos no 016/2008, sobre "terra: direitos patrimoniais e territoriais" inicia com a afirmação de que os povos e comunidades tradicionais, os povos indígenas e as comunidades quilombolas são sujeitos de direitos. Direitos assegurados pela Constituição Federal de 1988 e pelos tratados internacionais. O documento aponta diretrizes para a construção de políticas públicas de Estado para os PCTs em vista de garantir seus direitos patrimoniais, o uso sustentável da terra e a promoção da soberania alimentar. Enfatiza a necessidade de ações e programas voltados aos PCTs, em conformidade com o Decreto n 6.040/2007, que institui a PNPCT e esclarece que o uso do termo "terras" inclui a noção de territórios, o que abrange a totalidade do habitat das regiões que os povos interessados ocupam e/ou utilizam.

Entre as 26 recomendações de políticas públicas especificamente voltadas aos PCTs a Exposição de Motivos 016/2008 acentua: que seja assegurado o seu direito humano à alimentação adequada 
e a soberania alimentar; que as esferas governamentais respeitem, regularizem e executem os marcos legais constitucionais e os constantes nos acordos e tratados nacionais e internacionais; que seja garantido o direito de consulta prévia informada no caso de licenciamento e implementação de obras e empreendimentos sobre territórios tradicionais; que os ministérios reconheçam as especificidades dos PCTs; que o governo regulamente o acesso institucionalizado ao território dos povos e comunidades tradicionais (povos indígenas, quilombolas, ribeirinhos, seringueiros, extrativistas, pescadores artesanais, caiçaras, pantaneiros, geraizeiros, caatingueiros, ciganos, pomeranos, quebradeiras de coco babaçu, marisqueiras, faxinalenses, povos de terreiro, vazanteiros, piaçabeiros, comunidades de fundos de pasto, dentre outros ${ }^{3}$ ), reconhecendo as diversas modalidades de apropriação e uso tradicional das terras; que o governo viabilize a pesquisa nacional sobre PCTs e promova a recuperação de áreas degradadas nos territórios dos PCTs; que o Ministério da Justiça cumpra os prazos legais do Decreto 1775/1996 sobre identificação, delimitação, demarcação e contestações das terras indígenas; que o governo transforme em políticas permanentes vários programas sobre PCTs e articule o Congresso Nacional para a aprovação do Projeto de Lei que cria o Conselho Nacional de Política Indigenista e a aprovação do Estatuto dos Povos Indígenas; que o governo agilize os processos de identificação, reconhecimento, demarcação, regularização e titulação dos territórios quilombolas; que priorize a criação de políticas de Estado ao invés de programas de governo que venham a beneficiar os quilombolas; que execute as políticas públicas de forma intersetorial e promova ações afirmativas a curto prazo; que os programas de fomento à produção sejam desenvolvidos com base na agroecologia, na diversidade e no respeito às culturas alimentares tradicionais; que o governo garanta o acesso dos PCTs a todas as espécies de sementes e mudas que estão associadas ao conhecimento tradicional que vem sendo transmitido de geração em geração, fomente a produção de alimentos de acordo com a sua cultura alimentar e promova a biodiversidade.

Na Exposição de Motivos 010/2009 o Consea parte da especificação dos grupos que constituem os PCTs (já mencionados na EM 016/2008) e apresenta 19 proposições relativas à inclusão das diretrizes e princípios do etnodesenvolvimento nas políticas públicas de SAN e demais políticas correlatas para os PCTs, entre as quais menciona: a transformação em lei do Decreto 6.040/2007; a criação de marcos regulatórios de acesso institucionalizado aos territórios tradicionais e aos recursos naturais; a ampliação e consolidação, na forma de políticas públicas de Estado, das ações e programas específicos para a promoção do etnodesenvolvimento; a ampliação e consolidação de instrumentos legais que favoreçam o acesso dos PCTs às políticas públicas de caráter universal adequando-as às especificidades deste público; a criação de mecanismos de repasse de recursos da União adequados às especificidades de PCTs; a promoção de capacitação de PCTs para a cidadania; incentivo à produção que represente o conhecimento, a cultura e a 
soberania alimentar dos PCTs; a realização de levantamento socioeconômico e demográfico sobre PCTs; que o IBGE institua um censo específico para PCTs, crie departamento específico para trabalhar dados e informações concernentes a essas populações e adote novas categorias identitárias, a serem consideradas no ato de realização de suas pesquisas e levantamentos estatísticos; a capacitação de gestores públicos em todas esferas de governo sobre os direitos dos PCTs de forma a combater o preconceito étnico-racial e em políticas públicas; que o Ministério da Educação agilize a inserção de conteúdo relativo aos PCTs nos parâmetros curriculares da educação básica; que o Estado brasileiro, na implementação de grandes projetos de desenvolvimento, estabeleça mecanismos legais e participativos de licenciamento étnico-social, similar ao licenciamento ambiental; que o Estado brasileiro garanta a efetiva posse da terra e a regularização dos territórios dos PCTs; que o Governo brasileiro, por meio do Instituto do Patrimônio Histórico e Artístico Nacional (IPHAN), reconheça o patrimônio material e imaterial, legado da diáspora africana, expresso na utilização das plantas e alimentos tradicionais (formas de cultivo e preparo), na gastronomia e nas práticas de cura; que o governo apoie a aprovação do Projeto de Lei no 231/2007 (Lei do Babaçu Livre) e promova a proteção e o acesso dos PCTs aos babaçuais.

A Exposição de Motivos 008/2010 do Consea traz proposições especificamente relacionadas aos resultados do I Inquérito Nacional de Saúde e Nutrição dos Povos
Indígenas e às políticas de SAN no Brasil. São feitas 21 recomendações aos diversos órgãos públicos, especialmente nas áreas do fortalecimento de órgãos como a Funai e a Funasa, ampliação de recursos públicos para programas de saúde indígena e SAN, demarcação de territórios e outras, de modo a chamar atenção das autoridades governamentais diante da gravidade dos problemas de saúde e desnutrição que assolam o cotidiano dos povos indígenas.

Na Exposição de Motivos no 008/2011 o Consea reconhece o esforço do governo, das organizações indígenas regionais e de organizações não governamentais parceiras pela conclusão do processo de consultas públicas aos povos indígenas que contou com a participação de cerca de 1400 representantes em todo o Brasil e resultou na elaboração da proposta de Decreto presidencial que instituiu a Política Nacional de Gestão Territorial e Ambiental de Terras Indígenas (PNGATI) (Brasil 2012). O Consea solicitou a agilização da assinatura e publicação do Decreto que institui a PNGATI em caráter de urgência, para se avançar na garantia dos direitos dos povos indígenas.

Em um contexto de estagnação da política de reforma agrária no Brasil, na Exposição de Motivos 012/2011 o Consea ressalta o direito de acesso à terra como um dos mecanismos estruturantes de combate à fome e à miséria e de redução das desigualdades no campo brasileiro e de promoção do direito humano à alimentação adequada. São feitas 16 proposições para realizar esses direitos, entre as quais há diversas especificamente voltadas aos direitos dos PCTs: promover 
o acesso à terra e garantir a plena realização dos direitos territoriais e patrimoniais dos PCTs; acelerar processos de titulação, demarcação e homologação dos territórios indígenas e quilombolas, bem como revisar os instrumentos de recursos judiciais aos processos de demarcação das terras indígenas; instituir e garantir a implementação da PNGATI; reaparelhar e modernizar o Incra, a Funai, a Fundação Cultural Palmares e a Secretaria do Patrimônio da União; aprimorar a relação do governo com as organizações da sociedade civil na resolução dos conflitos territoriais e avançar na criação de marcos regulatórios para o acesso institucionalizado aos territórios tradicionais e aos recursos naturais dos quais os PCTs se utilizam.

Diante da iminência de retrocessos nas conquistas históricas de direitos dos povos indígenas, o Consea se manifesta através da Exposição de Motivos 003/2012 sobre a Proposta de Emenda Constitucional (PEC no 215/2000), aprovada em abril de 2012 na Comissão de Constituição e Justiça e de Cidadania da Câmara dos Deputados, que estabelece como competência exclusiva do Congresso Nacional a aprovação da demarcação das terras tradicionalmente ocupadas pelos indígenas, assim como a ratificação das demarcações já homologadas. O Consea avalia que a aprovação dessa PEC significaria a paralisação do processo de demarcação das terras indígenas e favoreceria a ampliação da concentração da posse e propriedade da terra no país, ferindo as conquistas democráticas consagradas na Constituição de 1988, que atribui à União a competência para demarcar, proteger e fazer respeitar todos os seus bens, entre os quais estão os territórios ocupados pelos povos indígenas. Finalmente, o Consea solicita empenho e participação ativa da Presidência da República na defesa do arquivamento da PEC 215/2000.

Nos últimos dois anos o Consea fez quatro recomendações fortes ao governo federal sobre temas específicos e urgentes relacionados aos povos e comunidades tradicionais, geralmente diante de situações de gravidade de violações de direitos, especialmente do direito humano à alimentação adequada. A Recomendação no 001/2011 recomenda "que o Incra conclua o processo de titulação do território das comunidades de Brejos dos Crioulos". A Recomendação no 001/2012 pede que o Supremo Tribunal Federal julgue improcedente a Ação Direta de Inconstitucionalidade - 3239, dirigida contra o Decreto 4.887/2003 que regulamenta o "procedimento para identificação, reconhecimento, delimitação, demarcação e titulação das terras ocupadas por remanescentes das comunidades dos quilombos de que trata o artigo 68 do Ato das Disposições Constitucionais Transitórias". A Recomendação 003/2012 "recomenda ao Ministério da Integração Nacional o fornecimento em caráter emergencial de água para consumo humano e animal para as aldeias indígenas do semiárido brasileiro em situação de estiagem". E a Recomendação $n^{0}$ 004/2012 ao Ministério do Desenvolvimento Social e Combate à Fome que a "distribuição das cestas de alimentos para as aldeias indígenas do semiárido brasileiro em situação de estiagem seja mensal". 
Em conformidade com o seu mandato, o Consea, sistematicamente, tem incluído em sua agenda de reuniões trimestrais o tema dos povos e comunidades tradicionais. Algumas dessas reuniões plenárias trataram de modo mais aprofundado esses temas e geraram os documentos referidos. $\mathrm{E}$ todos eles, mas especialmente as exposições de motivos, entre 2008 e 2012, são perpassados transversalmente por uma atenção especial às proposições e recomendações de caráter estruturante, sem com isso olvidar-se das questões emergenciais que são frequentes.

As exposições de motivos 016/2008 e 010/2010, especialmente, apresentam uma grande densidade de proposições sobre o direito à terra e ao território e ao etnodesenvolvimento. Tanto sua base teórica quanto as proposições feitas ao governo frisam o direito à terra e ao território, ressaltando o acesso e uso dos recursos naturais e produtivos, o respeito à autodefinição identitária e a explicitação nominal dos grupos, o respeito às suas tradições culturais e formas de organização social e representação, deixando claro que as identidades se constituem nos territórios e garantem sua reprodução social e material à medida que essas populações têm garantido o seu direito humano à alimentação. Deste modo o Consea, efetivamente, internaliza as demandas dos PCTs relacionadas à SAN e se constitui como um importante instrumento de interlocução e consertação entre governo e demandas dos diferentes atores da sociedade civil.

\section{DEMANDAS DOS POVOS E COMUNIDADES TRADICIONAIS EXPRESSAS NO PLANO NACIONAL DE SEGURANÇA ALIMENTAR E NUTRICIONAL}

$\mathrm{Na}$ primeira parte do primeiro Plano Nacional de SAN - 2012/2015 o governo faz uma ampla contextualização dos programas e ações em SAN desenvolvidos nos últimos anos no Brasil. De modo geral, os PCTs são bastante contemplados com políticas e programas gerais e específicos em SAN. Às vezes são populações explicitamente citadas e, com frequência, são enquadradas entre as populações que se encontram em situação de maior vulnerabilidade social e alimentar.

Com base em fontes do IBGE e de outros órgãos de estatísticas e fontes governamentais o Plano diagnostica, por exemplo: que a absoluta maioria das pessoas extremamente pobres (71\%) é negra (pretos ou pardos) e que $40 \%$ da população indígena está na mesma condição; que a proporção de insegurança alimentar e nutricional grave ou moderada é maior em domicilios cuja pessoa de referência é a mulher e as pessoas são pretas ou pardas; que há maior grau de insegurança alimentar e nutricional em domicílios com baixa escolaridade e estes dois índices são diretamente associados às populações negras e indígenas; que a saúde da população indígena e negra apresenta diversas vulnerabilidades e preocupações e tem sido objeto de ações específicas; que tem ocorrido ações de regularização fundiária de territórios quilombolas e demarcação de terras indígenas, mas que este permanece como um grande desafio; que pouco se avan- 
çou em termos de regularização de território dos demais povos e comunidades tradicionais (que são pouco citados pela sua autodefinição ao longo de todo Plano) pela falta de meios técnicos e jurídicos que lhes assegurem território; que vem crescendo as ações de conservação, manejo e uso da agrobiodiversidade voltadas para povos e comunidades tradicionais; e que vem se incrementando diversas ações específicas voltadas à alimentação escolar em escolas indígenas e quilombolas.

No capítulo 2 o Plano contempla 10 macrodesafios para se avançar no enfrentamento e superação da pobreza e garantir a realização do direito humano à alimentação adequada e à soberania alimentar no horizonte da implementação do Sistema Nacional de SAN (SISAN). O Plano reconhece que na erradicação da pobreza é preciso considerar que populações residentes em áreas rurais, domicílios chefiados por mulheres e povos e comunidades tradicionais estão mais vulneráveis à fome; menciona a valorização e proteção da agrobiodiversidade e aponta para um novo paradigma, marcado pelo uso racional dos recursos naturais e a preservação da biodiversidade, com produção agroecológica e garantia de acesso por parte de agricultores familiares, povos indígenas e comunidades tradicionais ao uso sustentável da agrobiodiversidade, bem como o reconhecimento de seus saberes e práticas no manejo dos recursos da biodiversidade; contempla a necessidade da reforma agrária, acesso à terra, demarcação, regularização e desintrusão de terras/territórios indígenas e quilombolas e de demais povos e comu- nidades tradicionais; trata da ampliação do mercado institucional de alimentos para a agricultura familiar, povos indígenas e povos e comunidades tradicionais e o respectivo abastecimento dos circuitos curtos de produção, abastecimento e consumo alimentar; destaca o acesso à água de qualidade e em quantidade, especialmente no semiárido brasileiro (e não menciona explicitamente populações tradicionais, mas sabe-se que vários grupos que se autodefinem povos e comunidades tradicionais vivem em territórios do semiárido).

O nono desafio chama atenção para o enfrentamento das desigualdades socioeconômicas, regionais, étnicoraciais e de gênero, mediante a compreensão e o trato de aspectos específicos dessas populações e regiões, e aí se afirma, por fim, o grande desafio dos povos indígenas, quilombolas e demais povos e comunidades tradicionais acessarem às políticas públicas de SAN e os serviços públicos de forma universalizada, com sua participação na construção e execução de políticas diferenciadas e específicas, com base nos princípios do etnodesenvolvimento e que respeitem a cultura e as estratégias de organização e reprodução social.

O capítulo 3 trata do SISAN e do marco legal para a sua implementação, no qual chama atenção para a importância da intersetorialidade das ações e programas de SAN e de políticas diferenciadas para populações específicas. O capítulo 4 menciona as oito diretrizes da Política Nacional de SAN em vista da realização do direito humano à alimentação adequada. 
A primeira diretriz visa à garantia do acesso universal à alimentação adequada e saudável e tem entre suas metas: o aprimoramento de estratégias de identificação e caracterização de famílias pertencentes a grupos populacionais diferenciados; qualificação da oferta de alimentação escolar em escolas situadas em áreas indígenas, quilombolas e de demais povos e comunidades tradicionais; fomento à aquisição de alimentos pelas escolas de povos e comunidades tradicionais; atendimento por meio da distribuição de alimentos, a comunidades remanescentes de quilombos, pescadores, comunidades de terreiros e outros grupos populacionais específicos.

A diretriz 2 trata da promoção do abastecimento alimentar e tem entre suas metas: adquirir produtos de extrativistas e pescadores para redistribuí-los a familias em situação de vulnerabilidade; acompanhar e disseminar informações sobre avaliações de safras, incluindo os modos de agricultura dos povos e comunidades tradicionais e os produtos da sociobiodiversidade; utilizar mecanismos de política agrícola no apoio à produção e comercialização de produtos oriundos de povos indígenas, quilombolas e demais comunidades tradicionais; ampliar a participação dos povos indígenas, quilombolas e demais PCTs no abastecimento dos mercados; valorizar os aspectos culturais e ambientais dos produtos oriundos dos PCTs; qualificar instrumentos de financiamento e fomento à produção dos PCTs, como acesso ao Pronaf e microcrédito direcionados a grupos e segmentos específicos; promover o acesso e qualificação dos serviços de assistência técnica aos PCTs; apoiar a estruturação da produção dos PCTs; estabelecer sinergias entre fomento à produção com a Política Nacional de Sociobiodiversidade; promover modelos de produção alimentar agroecológicos e de valorização da agrobiodiversidade e sociobiodiversidade; utilizar a abordagem territorial na promoção da integração das políticas públicas visando o desenvolvimento sustentável; fomentar a produção dos pescadores artesanais para o consumo interno; e adequar os serviços de segurança higiênico-sanitária na comercialização dos produtos dos PCTs.

A diretriz 3 trata da educação alimentar e destaca a promoção, valorização e respeito às especificidades culturais e regionais, realizada com ampla participação dos PCTs em profundo respeito às suas práticas alimentares. A diretriz 4 trata especificamente da "promoção, universalização e coordenação de ações de SAN voltadas para quilombolas e demais PCTs de que trata o Decreto 6.040/2007 e povos indígenas" (Brasil 2011b: 90). Entre seus objetivos e metas destacamse: a regularização fundiária de terras indígenas e quilombolas e respeito aos seus direitos territoriais; a implantação e desenvolvimento da Política Nacional de Gestão Ambiental e Territorial em Terras Indígenas; a promoção da SAN e do etnodesenvolvimento dos PCTs com uso sustentável da biodiversidade e a valorização da agrobiodiversidade e sociobiodiversidade; e a qualificação da saúde, alimentação e nutrição dos povos indígenas, quilombolas e demais PCTs.

A diretriz 5 contempla ações de alimentação e nutrição nos níveis de atenção à saúde articuladas com SAN e realça ações 
específicas direcionadas ao cuidado de doenças e/ou necessidades alimentares especiais de grupos populacionais específicos, como programas de suplementação de ferro e vitamina A e outros. A diretriz 6 cuida do acesso universal à água de qualidade e em quantidade suficiente. É direcionada aos estados do semiárido brasileiro que possuem uma grande diversidade de PCTs. Entre as metas e ações específicas estão: acesso à água nas escolas dos territórios tradicionais; acesso à água de consumo para a produção alimentar das famílias dos PCTs; ampliação dos serviços de saneamento básico e abastecimento de água dos territórios dos PCTs.

A diretriz 7 ocupa-se com o apoio a iniciativas de soberania, SAN e direito humano à alimentação na esfera internacional e a diretriz 8 estabelece mecanismos de monitoramento da realização do direito humano à alimentação adequada expressos ao longo das sete diretrizes anteriores deste Plano. Esta última diretriz se constitui em um instrumento fundamental de realização de direitos dos PCTs.

No esforço de se sumarizar as principais ações corre-se o risco de não contemplar todas. Uma leitura minuciosa do Plano certamente ampliaria, ainda mais, esta listagem de ações identificadas. Cabe destacar que a concepção do Plano Nacional de SAN segue uma lógica geral de incluir e contemplar ao máximo as demandas dos PCTs nas políticas e ações de SAN, o que fica bem evidente nas várias diretrizes do Plano, muitas das quais já estão em processo de implantação. Entretanto, percebe-se o uso recorrente ao longo do Plano da linguagem "povos indígenas, quilombolas e demais povos e comunidades tradicionais", o que se explica pela falta de marcos legais mais claros para esses "demais povos e comunidades tradicionais". No entanto, isso pode ser uma das razões desses grupos continuarem na invisibilidade, tanto identitária quanto no acesso equitativo às políticas públicas, permanecendo como um desafio a ser enfrentado nos termos que o Consea tem utilizado com maior frequência, ou seja, de nomear cada um dos grupos pela sua autodefinição ou então designá-los com uma denominação inclusiva. Não obstante estas diferenças, pode-se afirmar que o Plano Nacional de SAN incorpora as principais demandas oriundas dos povos e comunidades tradicionais relacionadas à SAN internalizadas e demandadas pelo Consea ao governo e seus 19 ministérios integrantes da Câmara Intersetorial de SAN responsável pela elaboração, implementação e monitoramento do Plano Nacional de Segurança Alimentar e Nutricional em vigor.

\section{CONSIDERAÇÕES FINAIS}

Por tratar-se de uma noção ainda em consolidação em um contexto de afirmação de direitos, indiscutivelmente, os povos e comunidades tradicionais emergem em um processo dinâmico que se expressa em tornar visíveis àqueles que historicamente eram mantidos na invisibilidade. Este movimento ancora-se em uma tríplice dimensão. Por um lado, cresce o interesse pela produção de literatura sobre o tema, especialmente nas ciências sociais e ambientais, com fundamentos teóricos e metodológicos para a compreensão deste complexo campo de atores sociais emer- 
gentes na sociedade brasileira. Por outro lado, em meio às controvérsias e disputas de interesses, ocorrem importantes avanços nos marcos jurídicos e normativos do Estado brasileiro que garantem um conjunto de direitos e políticas públicas aos povos e comunidades tradicionais. Finalmente, as duas razões anteriores não podem ser compreendidas isoladamente, mas em interconexão e retroalimentação com a organização sociopolítica e as formas de representação dos diferentes grupos que se autodefinem como povos e comunidades tradicionais e emergem como sujeitos na conquista de seus direitos.

A partir deste trabalho, identificam-se alguns macrodesafios que podem estimular a continuidade dos estudos sobre povos e comunidades tradicionais.

O primeiro macrodesafio consiste no aprimoramento da relação entre a dimensão jurídico-normativa e a dimensão das ciências sociais. Por mais que Santilli (2005) mencione que a noção de populações tradicionais seja relativamente bem aceita e definida entre os cientistas sociais e ambientais, entre eles permanecem diferenças de concepções que precisam ser aprofundadas, sem qualquer pretensão de se produzir enquadramentos teórico-conceituais sobre a pluralidade constitutiva e constituinte desses atores sociais. O desafio torna-se mais complexo à medida que se avança na formulação de uma definição jurídiconormativa, já que esta é uma precondição indispensável para o Estado formular e implantar políticas públicas que respondam às demandas históricas dos povos e comunidades tradicionais. Conforme se percebe no Plano Nacional de SAN, a ausência de marcos teóricos claros sobre certos grupos que se autodefinem como PCTs, além de mantê-los na invisibilidade identitária pode incorrer em dificuldades e limitações na definição e na operacionalização de políticas específicas voltadas à realização de seus direitos. Ainda que a noção de PCTs desenvolvida pelas ciências sociais seja gradualmente incorporada pelo ordenamento jurídico-normativo brasileiro, e seja compreendida a partir da interface entre biodiversidade e sociodiversidade, conforme propõe Santilli (2005), na prática este permanece como um campo de tensão positiva a ser administrado, em vista de se avançar nas formulações teóricas e práticas que incidem nas definições e na implementação de políticas públicas.

Um segundo macrodesafio consiste no aprimoramento das bases e condições de diálogo entre os atores institucionais e os atores sociais. A superação da razão instrumental pela razão comunicativa, no sentido habermasiano, realiza-se em contextos nos quais ambos os interlocutores estejam posicionados na condição de sujeitos que tenham algo a ouvir e algo a dizer, ou seja, em uma interação horizontal na qual se constituem os consensos em torno de interesses comuns. Ainda que os instrumentos normativos (como o SNUC, PNGATI, Decreto 6.040) enfatizem essa dimensão da participação ativa dos povos e comunidades tradicionais desde a elaboração até a gestão das políticas públicas de conservação e de SAN, nota-se uma relação assimétrica e fortemente hierárquica entre esses dois segmentos de atores, na qual o perigo da cooptação dos grupos locais deve 
ser considerado (Little 2002). Caberiam estudos mais aprofundados sobre tais relações para identificar em que medida elas efetivamente propiciam emancipação e autonomia ou dependência e novos paternalismos.

O terceiro macrodesafio relacionase com a necessidade de se avançar na criação de condições estruturais para que os povos e comunidades tradicionais vivam e utilizem seus territórios de acordo com suas tradições culturais. Ficou claro ao longo deste estudo que eles se caracterizam, especialmente, por cinco fatores: território, identidade, sistema de produção, organização social e tradições culturais. Assim, os programas e projetos de caráter mais emergencial são importantes e necessários, especialmente para garantir que os PCTs estejam livres da fome, mas a garantia de seus territórios é condição fundamental para a realização desses cinco fatores referidos e para a realização de seu direito humano à alimentação adequada e saudável na condição de sujeitos de direitos. ${ }^{4}$ Além de essas condições estruturais constituíremse em respostas às demandas das organizações dos povos e comunidades tradicionais, elas também representam boas respostas aos perigos ao etnodesenvolvimento identificados por Little (2002) e expressos no "projetismo" e no novo tipo de "paternalismo", caracterizados pelo monopólio de entidades externas sobre os grupos e entidades locais.

O quarto e último macrodesafio relaciona-se com os três anteriores e pode ser explicitado como a necessidade de se transformar ações e programas em políti- cas de Estado que respeitem, protejam e promovam os direitos dos povos e comunidades tradicionais. Com frequência essas populações têm sido objetos de ações, projetos e programas pontuais e não de políticas estáveis. Existem estudos e marcos legais nacionais e internacionais suficientes para justificar e embasar essa mudança paradigmática requerida do Estado brasileiro, de conceber, respeitar e tratar a diversidade de sua população com políticas diferenciadas mas com equidade de direitos.

\section{AGRADECIMENTOS}

À FAPERGS pela concessão da bolsa de doutorado, ao CNPq pelo financiamento do projeto sobre o Observatório Socioambiental em Segurança Alimentar e Nutricional (OBSSAN-RS, www.ufrgs.br/ obssan) e aos colegas do NESAN - Núcleo de Estudos e Pesquisas em Segurança Alimentar e Nutricional pela parceria na atuação junto à temática da Segurança Alimentar e Nutricional.

\section{NOTAS}

${ }^{1}$ CONSELHO NACIONAL DE SEGURANÇA ALIMENTAR E NUTRICIONAL. Exposição de Motivos no 016/2008. Terra: direitos patrimoniais e territoriais. Brasilia, 29 de outubro de 2008. Disponível em: http://www4.planalto.gov.br/consea/exposicao-de-motivos. Acesso em: 09 jan. 2013.

2 Organização Internacional do Trabalho. Convenção 169 sobre Povos Indígenas e Tribais. Disponível em: http://www.oitbrasil.org.br/content/ apresenta $\% \mathrm{C} 3 \% \mathrm{~A} 7 \% \mathrm{C} 3 \% \mathrm{~A} 3 \mathrm{o}$. Acesso em: 05 jan. 2013. 
${ }^{3}$ Além destes grupos, Alfredo Wagner de Almeida (2008) menciona outros sujeitos sociais emergentes com identidades coletivas a partir dos direitos territoriais e da "autoconsciência cultural".

${ }^{4}$ Em estudos recentes Dayrell et al. (2012) mencionam estudos de Alfredo Wagner que estima que os povos e comunidades tradicionais constituem uma população aproximada de 25 milhões e ocupam $1 / 4$ do território nacional, mas que um montante considerável desse território não é demarcado ou regularizado de modo que grande parte dessas populações não podem usufruir de seus direitos de modo adequado. Os autores analisam os dados do Mapa da Injustiça Ambiental e Saúde no Brasil (LIS/ICICT/Fiocruz 2013, disponível em:

http:/ / www.conflitoambiental.icict.fiocruz.br/. Acesso em: 21 mar. 2013), cruzados com os dados do Caderno Conflitos no Campo (2011) e constatam que $48 \%$ do total dos conflitos são diretamente relacionados aos PCTs. E mais, 54\% dos conflitos que envolvem PCTs estão diretamente relacionadas à defesa e proteção de seus territórios.

\section{REFERÊNCIAS}

Almeida, A. W. B. 2008. Terra de quilombos, terras indígenas, "babaçuais livres", "castanhais do povo", faxinais, fundos de pasto: terras tradicionalmente ocupadas. 2. Ed. Manaus: PGSCA/UFAM.

Barreto Filho, H. T. 2001. Identidades emergentes, soluções heterodoxas: o caso da (não) demarcação da Terra Indígena Tapeba, in Politica indigenista: Leste e nordeste brasileiros. Organizado por M. A. Espírito Santo, pp.27-39. Brasilia: FUNAI/CEDOC.

BRASIL. 1992. Portaria no 22/1992. Criou Centro Nacional do Desenvolvimento Sustentado das Populações Tradicionais.
Disponível em: http://www.ibama.gov. br/. Acesso em: 06 jan. 2013.

2000a. Ministério do Meio Ambiente. Convenção sobre Diversidade Biológica. Brasília: MMA.

2000b. Lei $n^{\circ}$ 9.985, de 18 de julho de 2000. Regulamenta o art. 225 , par. $1^{\circ}$, inciso I, II, III e VII da Constituição Federal, institui o Sistema Nacional de Unidades de Conservação da Natureza. Disponível em: http://www.planalto.gov.br/ccivil_03/ leis/L9985.htm. Acesso em: 07 jan. 2013.

2001. Medida Provisória n 2.186-16, de 23 de agosto de 2001. Dispõe sobre acesso ao patrimônio genético e outras providências. Disponível em: http://www.mct.gov. br/index.php/content/view/3777.html. Acesso em: 08 jan. 2013.

2004. Decreto $n^{\circ} 5.051$, de 19 de abril de 2004. Promulga a Convenção no 169 da Organização Internacional do Trabalho OIT sobre Povos Indígenas e Tribais. Disponível em: http://www.planalto.gov.br/ ccivil_03/_ato2004-2006/2004/decreto/ d5051.htm. Acesso em: 07 jan. 2013.

2006. Decreto de 13 de julho de 2006. Altera a denominação, competência e composição da Comissão Nacional de Desenvolvimento Sustentável das Comunidades Tradicionais e dá outras providências. Disponível em: http://www.planalto.gov.br/ ccivil_03/_Ato2004-2006/2006/Dnn/ Dnn10884.htm. Acesso em: 26 mar. 2013. 2007. Decreto $n^{\circ}$ 6.040, de 7 de fevereiro de 2007. Institui a Política Nacional de Desenvolvimento Sustentável dos Povos e Comunidades Tradicionais. Disponível em: http://www.planalto.gov.br/ccivil_03/_ ato2007-2010/2007/decreto/d6040.htm. Acesso em: 07 jan. 2013.

2011a. Constituição da República Federativa do Brasil. Brasília: Senado Federal. 
2011b. Câmara Interministerial de Segurança Alimentar e Nutricional. Plano Nacional de Segurança Alimentar e Nutricional: 2011/2015. Brasília, DF: MDS, Consea.

2012. Decreto $n^{\circ} 7.747$, de 5 de junho de 2012. Institui a Política Nacional de Gestão Territorial e Ambiental de Terras Indígenas - PNGATI, e dá outras providências. Disponível em: http://www.planalto.gov. br/ccivil_03/_ato2011-2014/2012/decreto/d7747.htm. Acesso em: 12 set. 2013.

Exposição de Motivos n 010/2009. Diretrizes para o Etnodesenvolvimento. Brasília, 27 de novembro de 2009. Disponível em: http:/ /www4.planalto.gov.br/ consea/exposicao-de-motivos. Acesso em: 09 jan. 2013.

Exposição de Motivos nº 008/2010. I Inquérito Nacional de Saúde e Nutrição dos Povos Indígenas Brasília, 23 de junho de 2010. Disponível em: http://www4. planalto.gov.br/consea/exposicao-de-motivos. Acesso em: 09 jan. 2013.

Exposição de Motivos no 008-2011. Política Nacional Gestão Territorial e Ambiental de Terras Indígenas. Brasília, 04 de julho de 2011. Disponível em: http:// www4.planalto.gov.br/consea/exposicaode-motivos. Acesso em: 09 jan. 2013.

Exposição de Motivos no 012/2011. Reforma agrária e direitos territoriais. Brasília, 14 de setembro de 2011. Disponível em: http://www4.planalto.gov.br/consea/exposicao-de-motivos. Acesso em: 09 jan. 2013.

Exposição de Motivos no 003/2012. Proposta de Emenda Constitucional 2015/2000. Brasília, 15 de maio de 2012. Disponível em: http:/ /www4.planalto.gov. br/consea/exposicao-de-motivos. Acesso em: 09 jan. 2013.

Recomendação do CONSEA N ${ }^{\circ}$ 001/2011. Brasília, 11 de maio de 2011.
Disponível em: http://www4.planalto.gov. $\mathrm{br} /$ consea/exposicao-de-motivos. Acesso em: 09 jan. 2013.

Recomendação do CONSEA $n^{\circ}$ 001/2012. Brasília, 18 de abril de 2013. Disponível em: http://www4.planalto.gov. br/consea/exposicao-de-motivos. Acesso em: 09 jan. 2013.

Recomendação do CONSEA 003/2012. Brasília, 28 de maio de 2012. Disponível em: http://www4.planalto.gov. br/consea/exposicao-de-motivos. Acesso em: 09 jan. 2013.

Recomendação do CONSEA 004/2012. Disponível em: http://www4. planalto.gov.br/consea/exposicao-de-motivos. Acesso em: 09 jan. 2013.

Coelho-de-Souza, G. \& R. R. Kubo. No prelo. Etnodesenvolvimento: a inserção da diversidade étnica no debate sobre Desenvolvimento, in Pesquisa em Desenvolvimento Rural: aportes teóricos e proposições metodológicas. Organizado por M. A. Conterato, G. W. Radomsky \& S. Schneider. Porto Alegre: Editora da UFRGS.

Coelho-de-Souza, G.; J. B. Bassi \& e R. R. Kubo. 2011. Etnoecologia: dimensão teórica e aplicada, in Transformação no espaşo rural. Organizado por G. Coelho-deSouza, pp. 25-47. Porto Alegre: Editora da UFRGS.

Costa Filho, A. 2007. Povos e comunidades tradicionais. Brasília: MDS.

Cunha, M. C. \& M. Almeida M. 2013. Quem são as populações tradicionais? Disponível em: http://uc.socioambiental. org/territórios-de-ocupação-tradicional/ quem-são-as-populações-tradicionais. Acesso em 10 mar. 2013.

Dayrell, C. A., J. B. Costa \& A. Costa Filho. 2012. Direitos humanos e povos tradicionais no Brasil, in Direitos humanos no Brasil 
3: diagnósticos e perspectivas. Organizado por Movimento Nacional de Direitos Humanos, Plataforma DhESCA Brasil, Processo de Articulação e Diálogo, Parceiros de MISEREOR no Brasil, pp. 417-442. Passo Fundo: IFIBE.

Diegues, A. C. 1996. O mito do paraíso desabitado. Revista do Patrimônio Histórico e Artístico Nacional 24:141-151.

Diegues, A. C. \& R. S. V. Arruda (Orgs.). 2001. Saberes tradicionais e biodiversidade no Brasil. Brasília: Ministério do Meio Ambiente; São Paulo: USP.

Hissa, C. E. V. 2008. Saberes ambientais: a prevalência da abertura, in Saberes ambientais: desafios para o conbecimento disciplinar. Organizado por C. E. V. Hissa, pp. 47-63. Belo Horizonte: Editora UFMG.

Little, P. E. 2002. Etnodesenvolvimento local: autonomia cultural na era do neoliberalismo global. Tellus 2(3):35-52.

Santilli, J. 2005. Socioambientalismo e novos direitos: proteção jurídica à diversidade biológica e cultural. São Paulo: Peirópolis.

Viana, V. M. 2004. Envolvimento sustentável e conservação das florestas brasileiras, in Comunidades tradicionais $e$ manejo dos recursos naturais da Mata Atlântica. Organizado por A.C. Diegues e V.M. Viana, pp. 23-26. $2^{a}$ edição. São Paulo: HUCITEC:NUPAUB:CEC.

Recebido em 24/06/2013.

Aprovado em 02/08/2013. 